\title{
18
}

\section{What Remains Unwritten? Developing a Critical Evaluation of Multi-level Governance and its Futures in Australian Public Policy and Politics}

\author{
Katherine A. Daniell and Trish Mercer
}

\section{Paying attention to the unwritten}

This book has a vocation to raise awareness on forms of multi-level governance (MLG) in Australian public policy and associated politics. As an overview of key observations from the conceptual and case study chapters has already been provided in large part in the introduction, this conclusion instead focuses on issues that are yet to be raised.

Among the potentially long list of untreated issues, we have elected to focus on three key themes. First, we investigate the counter-evidence to the development of MLG approaches and how, where and when 'nonnegotiable' inflexible approaches to governance across levels are most likely to flourish, using examples from national policy initiatives. Second, we investigate the issue of research practice and methodologies employed in studying MLG processes presented in and beyond this volume, which have yet to be systematically elicited. These two investigations allow us to postulate why certain case studies have appeared in this volume and not 
others, as well as why there is a relatively large gap between the theoretically focused and case study example chapters. It then leads us into a final section of new theorisation to state the conditions - or rather cultures and political value systems - under which different types of MLG systems may appear and be reorganised. We can hence postulate where such systems will likely have the brightest and darkest futures across Australia's public policy and political system, and to what extent future research and focus on specific MLG practice may or may not prove fruitful.

\section{Investigating a relative absence of MLG}

To understand where there is an absence of MLG in Australia, we return to the definitions of MLG processes provided in Chapter 1 (Daniell and Kay), which we took as being systems of 'continuous negotiation among nested governments at several territorial tiers' (Marks 1993: 392) where there is not only a vertical dispersion of authority between levels of administration, but also a horizontal dispersion across different sectors of interest and spheres of influence, including non-government actors, markets and civil society (Bache and Flinders 2004; Daniell and Kay). We are thus theoretically looking for governance systems that are controlled by specific actors where there is little to no (obvious) ongoing negotiation about how policy development and implementation does, or will, function. We consider that the most likely places to find such systems are where: (a) negotiations have broken down, reached a stalemate, trust has evaporated or led to a lack of progress that results in a crisis and need for an actor to take urgent unilateral action; (b) the policy issue is so minor that it is of little interest to any more than one main actor; or (c) where one particular actor is so powerful that they do not need to negotiate but can effectively direct or coerce other actors to perform the governance activities they desire.

From an analysis of policy sectors in Australia, we have struggled to identify clear examples of minor policy issues (b), since the large majority of policy decisions will affect someone or some group's interests. We still theorise that such 'routine' policy areas likely do exist where bureaucrats can propose small policy changes that will pass through government approval processes with little interest or criticism from anyone inside or outside government. Areas such as municipal rubbish collection in regional areas could be an example, although there will always be some stakeholders 
who hold views on how it could or should be done differently. In federal governance systems, we propose that such situations are more likely in policy areas where 'coordinate' federalism can exist; that is, where there is little to no jurisdictional overlap and tiers of government can operate largely separately (Mulgan). In the other two categories, however, especially on largely non-negotiated policy responses to crises (a), sometimes with an element of powerful and directive leadership (c), examples are more plentiful.

For example, in the controversial area of gun control, we can see the pivotal influence of a specific actor on an area of policy stalemate. Proposals for uniform gun laws were discussed intermittently at the Commonwealthstate level from 1969, but had failed to progress given state government reluctance and opposition from pro-gun interest groups (Prasser 2006). In April 1996, the murder of 35 people at Port Arthur by a lone gunman with a high-powered semiautomatic gun was the catalyst for a major Commonwealth policy initiative. John Howard, the newly elected prime minister, acted decisively and with great speed to secure agreement from both the Commonwealth parliament and state and territory governments to the standardisation of firearms legislation and an accompanying gun buyback of newly illegal weapons from their owners. While Howard was not in the end required to act unilaterally, he was nonetheless prepared to employ media reports of a possible referendum in order to win agreement from the second tier of government to act together, given the overlapping federal and state jurisdictional responsibilities in this area. A policy impasse had thus been broken by the actions of a strong player who has been credited with managing both the politics and the policy effectively to achieve significant reform, although the actual impact of the National Firearms Agreement on firearm deaths continues to be debated (Prasser 2006; Leigh and Neill 2010).

In a similar way, the global financial crisis (GFC) of late 2008 provided Labor Prime Minister Kevin Rudd with the impetus for the federal government to drive through the national Home Insulation Program (HIP) as part of the GFC economic stimulus package. In the lead-up to the GFC, there had been joint Commonwealth-state work on energy efficiency initiatives but, with flagging economic confidence and the prospect of a sharp increase in unemployment, the Rudd Government decided to act unilaterally and took a deliberate decision not to involve state governments in order to roll out HIP within extremely tight time frames. The HIP was closed in February 2010, following the tragic deaths 
of four young insulation installers and more than 200 house fires related to the program. In their analysis of the HIP's limited achievements and massive failures, Hamdhan and Lewis (2013) underline the truncated nature of the consultation process, including minimal input from state and territory officials and key industry stakeholders.

The Royal Commission, appointed by the following Coalition Government under Tony Abbott to inquire into HIP, forensically analysed the program's failures and also drew attention to the Commonwealth's failure to engage directly with the states and territories, which held the regulatory powers for occupational health and safety (Hanger 2014). In 2015, the report Learning from Policy Failure into three major government policy initiatives (all conveniently under the Labor leadership of Rudd and Julia Gillard) by Peter Shergold (formerly head of the Department of Prime Minister and Cabinet), concluded that a major factor underpinning the poor decisions made in the program was failure in the operation of the Cabinet, with decisions being taken by a Cabinet committee that did not include the line minister (Shergold 2015). Whereas Howard reaped the political benefits of strong leadership in a crisis on a contested policy issue, Rudd's similarly decisive actions in a rather less contested policy area (but one seen to be owned by the state governments) had disastrous political and human implications.

Before discussing what we can take away from these insights in terms of the role of MLG, or lack thereof, in Australia, it is also worth mentioning two other examples that arise from chapters in this book. The first is the case of the Murray-Darling Basin takeover by the federal government (Daniell et al.). This followed a similar path to the previous two examples where the 'Millennium drought' and catastrophic state of the basin's environment and communities provided the state of crisis, motivation and window of opportunity for Water Minister Malcolm Turnbull to push through the national Water Act 2007, which would establish the federal MurrayDarling Basin Authority (MDBA) to manage the basin's water resources, doing away with the previous state-, territory- and Commonwealthnegotiated arrangement of the Murray-Darling Basin Commission. After a shaky start and retreat by the MDBA from negotiating with the basin's stakeholders while working on an 'evidence-base' for water planning which resulted in the parliamentary inquiry into the guide to the draft of the Murray-Darling Basin Plan (see Daniell 2011; Crase 2011) - MLG and more collaboratively negotiated operating mechanisms returned in order to ensure the passage of the initially heavily contested basin plan. 
The other policy area to consider is that of Indigenous affairs and to what extent the heavily negotiated and flexible ways of working described in Jarvie and Stewart can be taken into account considering that, soon after the collaborative Council of Australian Governments (COAG) Policy Trials (2002-07), came the unilateral Northern Territory (NT) National Emergency Response or 'The Intervention' (see Hunter 2007; Sanders 2008). This time the crisis point and call to action was taken up by Minister Mal Brough, a former army officer (Stewart and Jarvie 2015), with the strong endorsement of Prime Minister Howard, following the release of a report into widespread child abuse in NT Aboriginal communities (Wild and Anderson 2007). Discussion, relationship-building and the approach of working in partnership with Indigenous communities and their leaders dramatically halted when, following the passing of federal legislation with bipartisan political support, the Australian Defence Force (ADF) and an army of public servants (for approximate numbers, see FaHCSIA 2011) were sent into the Northern Territory to improve security, health and living conditions in Indigenous Australian communities there.

The Intervention was headed by Major General Dave Chalmers as a 'nonforce' operation, but soon became so controversial that the ADF wanted the role handed over to a civil servant (James 2007). Stewart and Jarvie (2015), through policy evaluation of these programs, outline that many of the public servants involved were just happy to get back to their traditional roles of doing things and seeing tangible outputs of their work, rather than building relationships and having to rely on different skills to ensure some progress was being made, as was the case under the COAG Murdi Paaki trial (Jarvie and Stewart). They also highlight how policy lessons from the trial's evaluations were unlikely to be taken up by government in subsequent phases of policy reform, which was due in large part to bureaucratic forms and cultures that do not lend themselves easily to 'working across boundaries' or reflecting on and amending practices when they may no longer suit the prevailing political winds.

What we see instead in these examples is a government - with sufficient strength of political leadership - taking the opportunity, often when policy progress is perceived to stall and/or negotiations break down, to revert to a command-and-control hierarchical approach to management that is inherent in its bureaucratic design, with the negotiation arena restricted to government bodies and their close allies. These examples also help to illustrate policy-framing contests in MLG systems, and how different framings of policy at different levels can be detrimental to building high trust and continuous negotiation. 
In terms of intergovernmental relations, in 2006-07, the Coalition Government was facing a phalanx of Labor-led state and territory governments and this final term in office was marked by strong central government initiatives by Howard (Walter 2010). In the NT Intervention, there was typically some negotiation between levels and sectors (e.g. a range of federal government departments, ADF, the NT Government and some service providers) and some MLG occurring, but this was strongly skewed to the powerful federal government interests (rather than community or private stakeholders), and to where the money and resources that could be quickly thrown at the policy issue lay. In the case of the Rudd Government's HIP, the Commonwealth's drive for pushing the program through was to contribute to a macro-economic policy strategy in a time of crisis. The effort was, in its entirety, arguably successful in its main objective of helping the Australian economy to avoid recession. It was deeply flawed, however, at the state and local level due to its rushed and unilateral implementation, without adequate negotiation, which proved to be the program's downfall.

It is here that the study of governance systems with a relative absence of negotiation across a broad range of policy stakeholders connects clearly to the observations of Australia's federalism literature. In particular, we can see linkages around issues of power and resources that can set in train systems of coercive federalism, rather than the more pragmatic, collaborative or cooperative forms that exist at times within COAG and other flexible and negotiated systems (Mathews 1977; Hollander and Patapan 2007; Fenna 2012; Smullen 2014; Kay; see also Mercer and Jarvie for another collaborative COAG working example). We also see how blurred responsibilities in many areas can lead to tension (see also Painter 2001; Fawcett and Marsh; and Mulgan on accountability), slow progress and a political willingness to 'cut through' with unilateral action to solve the impasse and attempt to 'get the job done' by controlling and directing its implementation. This appears to be particularly prevalent when the political complexion is polarised between the Commonwealth and the next tier of government - intuitively because of the greater likelihood of negotiations breaking down due to differing core values.

There thus remains a dream of being able to centralise power in Australia, as in other countries, with a unified system of government, which is most often lived out here through periods of crisis and is increasingly being enacted little by little (see Fenna 2012 or Smullen 2014 for a more nuanced interpretation). It is also the moment when a governing mentality 
of 'welfare statism' and the need for strong government intervention to support social development and security, more common in the 1950s, again becomes more acceptable to the voting public (see Dugdale for more discussion on this 'governmentality'). In a real crisis, like a natural disaster, there is a general hope that the government and army will pitch in to protect and help people to recover with dignity; they are our risk managers of last resort (see Matthews 2009).

Thus, in terms of what was largely unwritten in this volume, we can see here that MLG systems in Australia can break down and away from collaborative flexible forms (Type II), be replaced by more traditional bureaucratic forms of MLG (Type I) or, on occasion, be a governance system outside this classification. We have presented some initial thoughts on why such moves might be made due to political impetuses linked to crises (which can be real or concocted) and perceived complications of negotiating with diverse policy stakeholders. This, however, raises a deeper underlying question about the evolution of MLG types and systems: specifically, what general configurations of MLG are found where (i.e. policy domains and countries/regions), and how and why do they reconfigure between types over time?

We cannot hope to respond to this question fully in this chapter and, in fact, it could form the basis for many future volumes. Posing it, however, does lead us into discussing another element of the work in this volume that remains largely unwritten - the issue of research methodologies used to develop the work and case studies on MLG processes. We will first reflect on this, before providing some preliminary thoughts and analyses on the aforementioned question.

\section{MLG systems research practice: Emerging methodological possibilities}

As explained earlier in this book, we consider MLG to be processes of ongoing negotiation across boundaries. These processes are influenced by institutional and administrative structures at a range of levels and across sectors. Some of these structures, especially the cross-jurisdictional ones like COAG or regional management groups (e.g. for natural resource management or regional development), and how they support or constrain effective cross-boundary working, are studied in the case 
study chapters. The researchers of these chapters focus on the 'practice' of policymaking and how different forms of working can lead to changes in policy support structures and a range of both internal (i.e. for the negotiating actors involved) and external outcomes (i.e. the impacts of the policy). In a number of cases, authors also look at the quality of the coordination between actors from different jurisdictions and groups, and how they work (or fail to effectively work) together across a range of typical boundaries, including departmental, sectorial, government level and administrative area, public-private and official-community member. Coupled to this analysis is a focus on the factors that supported and enabled this coordination, or led to its demise, such as legislative or political changes and leadership or the support of champions (see Daniell and Kay for a more in-depth analysis on the book's contributions).

Here we maintain a critical stance and ask: how did the authors carry out this analysis of practices, structures, negotiations and interpreting the different stages of policy development through MLG practice? And, how might researchers interested in MLG processes go about analysing them in the future?

For the most part, our authors are silent on the research methods they used, except to note in a number of cases their involvement as policy actors who were themselves taking part in many of these negotiations (see, for example, Dugdale; Mercer and Jarvie; Hogan; Jarvie and Stewart, Iwanicki et al.; Andrews). Some of the methods or data collection tools can, however, be implicitly determined from the text, such as the use of archival analyses that has been focused by some level of involvement in the policy area over many years (e.g. Troy; Hogan); literature-based reviews, with or without case examples from experience and/or the literature (e.g. Kay; Fawcett and Marsh; Mulgan; Kerr; Dugdale; Daniell et al.); comparative policy or institutional analyses (e.g. Ross; Norman and Gurran; Andrews; Dale et al.); and personal recollections of process and structure design and negotiations, coupled to meeting notes and other records (e.g. Mercer and Jarvie; Jarvie and Stewart, Andrews).

We see in Andrews, for example, comments such as 'it was necessary for the group to first design an appropriate framework', implying that Andrews was part of 'the group' involved in designing and negotiating the MLG processes for management of the Lake Eyre Basin. She then clarifies the role she played personally in different phases of the process, helping to establish the viewpoint of her analyses, and draws on archival records (reports and papers) from the process that provide the data for 
her comparative analyses of two instances of multi-level working, using definitional components of MLG from a number of authors (e.g. Peters and Pierre 2004) to draw her conclusions. Participant observation during negotiations, plus informal discussions with others involved in these processes, were thus also likely to contribute to the data relied upon to construct the 'rich' case descriptions that border on ethnographic methods in this chapter and others.

Since 'behind-the-scenes' negotiations of the types common in MLG, or any other policy change process, are notoriously difficult to research (Daniell et al. 2014), this book contributes some useful and original contributions to the literature because many of the authors have been embedded themselves in the processes they have studied and have thus had valuable insight into these processes that outside researchers may find hard to gain. For others to emulate such studies, however, it is important to discuss the kinds of research methods that were used with varying degrees of rigour in these studies, which could be applied to the study of similar MLG processes in the future. Although MLG has been conceptualised largely through the political science literature, its emphasis on actors and the processes of interaction and collective construction of policy between them across scales and levels means that it is well placed to profit from the use of actor- and process-focused research methods from not only the political sciences, but also disciplines such as sociology, anthropology, linguistics, psychology and the management sciences (see also Fawcett and Marsh).

In particular, and as with the study of policy translation (Mukhtarov and Daniell 2017), MLG analysis could benefit from greater use of 'engaged' research approaches and associated methods. Specifically, methods where researchers are embedded close to, or participating in, the negotiating action will be vital to understanding MLG processes better. These include ethnographic and 'follow-the-policy' methods (e.g. Mosse 2004, 2011; Peck and Theodore 2012), as well as alternative appellations such as 'mobile methods' (McCann and Ward 2012) and the need to 'study through' policy and governance systems to understand 'tracing ways in which power creates webs and relations between actors, institutions and discourses across time and space' (Wedel et al. 2005: 40). Indeed, many 'interpretative policy methods' more generally fit this mould and would be most applicable to uncovering the tensions and reflecting the values in discourses that occur through the negotiation processes of MLG (e.g. Yanow 2000; Wagenaar 2006; Hendriks 2007). 
Other research approaches from an alternative body of literature the management and decision sciences - could also prove useful for uncovering and understanding negotiation processes. Specifically, the use of 'intervention research' is another engaged research approach that could be pursued by researchers interested in the inner workings of MLG systems. Intervention research is defined as 'purposive action to create change' (Midgley 2000). Unlike some of the interpretive methods, it purposely emphasises the need for an abductive approach (cycles of deductive and inductive work) via the use of models or 'rational myths' that shape and can be tested in interventions to create 'actionable knowledge' (Hatchuel and Molet 1986; David 2000; Daniell 2012). As outlined and used in Daniell et al. (2014) for investigating the politics of innovation in MLG systems by actors taking part in or organising policy negotiations, such an approach can allow access to behind-the-scenes struggles, as well as provide insight into why MLG system negotiations may break down and, ultimately, exclude some actors and preference others.

Both of these groups of approaches rely on similar data collection techniques such as field notes, reports, participant observation, records of communications (emails, letters, media, meeting and workshop notes, photos, videos and audio recordings), interviews, oral histories and questionnaires, but have slightly different underlying philosophical positions. We can see elements of these reflected in some of the case studies previously outlined. Specifically, an approach closer to intervention research is evident in Jarvie and Stewart, Andrews, Mercer and Jarvie and Iwaniki et al. - due to the use of policy and 'ways of working' model creation and testing - where the researchers were policy practitioners who set out to create change, but also developed and reflected on their knowledge creation to inform future action.

What is valuable in these approaches is the reflexivity that it promotes for policy actors and researchers around their own practices and impacts. The ethical issues associated with such research can, however, be complicated, especially when such policy and governance projects are not framed as traditional research projects at the beginning of their life and are thus not subject to ethics approval. Rather, the lead researchers were at the time subject to other codes of conduct, such as that of the Australian public service, and they subsequently needed to consider how to avoid breaching those codes (e.g. through breaking of confidence), as other public figures do when they research and write their memoirs and analyse certain events in which they have played a role. 
We consider, as has been discussed at greater length in Daniell et al. $(2009,2014)$, that there is no easy way to deal with some of these ethical complexities, but being upfront about them and reasoning them through (including what aspects of processes should be revealed and how people are identified) will allow such research approaches to take their place alongside the more established policy and governance research methods. Indeed, encouraging this kind of research and reflexivity about policy practice in the future could help not just the research community but also be of benefit to policy actors in government and other spheres of influence to enhance a culture of policy learning, evaluation and experimentation. It is also a productive avenue for the development of academic-practitioner partnerships around public policy, which could help both groups reflect on and learn from policy interventions leading to future improvement.

\section{New perspectives on MLG and transitions between systems}

Drawing on various illustrations of MLG from the authors of this book - and on a number that are obviously missing - and what their synthesis can tell us, we wish to reflect in this section on the question posed earlier on the evolution of MLG types and systems, as well as where they are most commonly found in the Australian context.

First of all, we postulate that Type I MLG systems are more likely to be found and thrive in the older and potentially more entrenched policy areas such as health, education, industrial relations, defence and traditional or long-lived public services (e.g. urban and rural infrastructure, such as roads, sewerage, water and electricity supply). In part this is due to the long-term responsibility for these areas that has been enshrined as part of constitutions and the sovereign realm of certain jurisdictions. This sets up a particular dynamic of state- and/or federally led negotiations that can often become institutionalised. It is not that simple, however, as there are many examples of pockets of more flexible Type II processes that operate during periods of reorganisation or when there is a need to integrate an innovation (e.g. integrating early childhood education into the policy domain of Australian education; see Mercer and Jarvie). In a similar vein, we observe that newer issues without obvious constitutional recognition are more likely to find themselves in a Type II MLG configuration, which is similar to why MLG Type II processes evolved in the European Union (EU). These include issues and policy areas such as 
telecommunications and internet regulation (including cyber security), extreme events and pandemics and climate change. Such areas often require negotiations across a broad range of actors in a non-hierarchical and fluid manner, as actors with the up-to-date knowledge, capacity and authority to act are split across the public, private and community sectors.

In other long-term 'wicked' policy issues, such as sustainable development (e.g. managing the health and functionality of the environment in the face of pressures for human and economic development), overcoming Indigenous disadvantage and security and migration issues, we are more likely to see significant flip-flopping between Types I and II of MLG as progress in either form advances, but not as desired by different interests.

Specifically, and as already alluded to (Daniell and Kay), MLG Type II arrangements are flexible but can also be fragile in response to changes in support from participating parties, leading to changes in structures and practices of negotiation. Change and learning to work differently with a variety of actors continuously over time can be tiring, and require a special set of unique skills (Stewart and Jarvie 2015; Jarvie and Stewart, Mercer and Jarvie; Daniell et al.). This means that events such as the loss of leaders and champions in different jurisdictions can lead to breakdown of the MLG negotiation system and installation of an alternative, as described earlier. Breakdowns in trust (i.e. to negotiating in good faith) can also lead to the need for a modified MLG system (see Dugdale on the need for 'high-trust' governance environments).

Institutionalisation of cross-boundary structures can help to support MLG system maintenance for slightly longer periods (see, for example, Norman and Gurran on regional groups for urban and coastal planning; or McNaughton and Lockie on GLOBALG.A.P.). The form of negotiations may still vary over time, however, depending on the complexity and flexibility of these structures and what subsidiary working structures they create (e.g. the COAG examples in Mercer and Jarvie and Stewart). In a national context, we observe that it can prove difficult for a federal (or state) government to manage multiple MLG Type II negotiation processes around a particular policy with different stakeholders across a specific region, especially when there are varying levels of conflict and capacity for effective governance.

Once either MLG negotiation systems begin to fail or frustration (real or manufactured) by federal level policymakers and politicians sets in (e.g. in Indigenous policy or the managing of the Murray-Darling Basin) 
it appears that, rather than re-resourcing these systems to improve their functionality, the desire for one centrally enforced (or 'one-size-fits-all') policy becomes stronger. The switch to a less flexible MLG Type I system (or even to an absence of MLG systems (MLG Type 0)) with clearer lines of authority and accountability can then be enacted when an appropriate window of opportunity opens.

This fluctuation of MLG types in certain policy areas also appears to underline the challenge of Australian society's competing cultural values over how we ought to be organised, who ought to be responsible for decision-making and what kind of justice regime we ought to enact through these decisions and specifically for where. ${ }^{1}$ Indeed, different forms of competing MLG types can be mapped onto the hierarchist, individualist, egalitarian and fatalist cultural types (also known as GridGroup Cultural Theory; see, for example, Douglas 1978; Wildavsky 1987; Thompson et al. 1990; Tukker and Butter 2007; Daniell 2014), as presented in Figure 18.1.

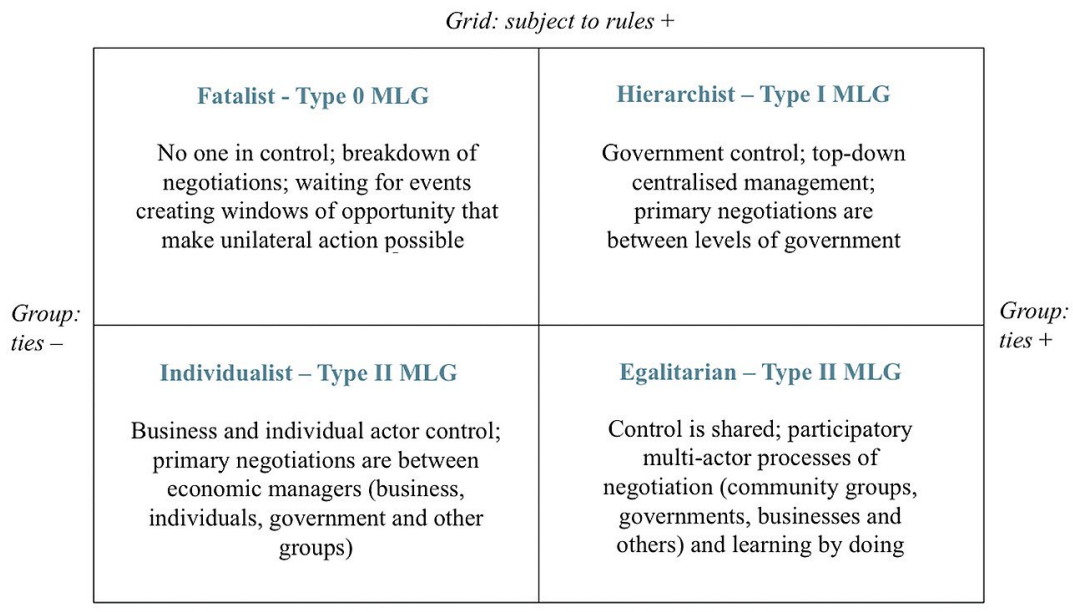

Grid: subject to rules -

Figure 18.1: MLG cultural typology (based on Grid-Group Cultural Theory)

Source: Katherine A. Daniell and Trish Mercer

1 This reflects the politics of who wins and loses and, specifically, Lasswell's (1936) question of who gets what, when and how. Due to the importance of claims of territorial justice in many MLG cases, this needs to be supplemented, however, by the question of 'where'. 
In any society or political system there is the potential for all of these types - related to the strength of relationships between people (Group ties) and the strength of rules governing individual behaviour (Grid: subject to rules) - to be represented and in tension at the same time, with politics helping to establish which ones take preference in different policy areas and at different times. As shown in Figure 18.1, the type of negotiations set up in a hierarchist system are likely to be those in and between functioning bureaucracies at different administrative levels.

These could be most easily likened to a Type I MLG system, although it does not represent all Type I configurations that may not be hierarchical or centralised as such (see Hooghe and Marks 2003). In an egalitarian system, MLG negotiations are more likely to be inclusive of participants with an interest in the policy area, regardless of which sector or group they represent. The focus would be on working together (for the 'common good') and establishing horizontal rather than vertical accountability (see Mulgan). This is representative of a Type II MLG system. In an (ideal) individualist system - another Type II MLG system - negotiations in the governance system would be between individuals, businesses and other groups seeking to maintain and enhance their own interests and freedoms (rather than focusing on the common good).

Finally, the fatalist category represents the discussion earlier in this chapter of the breakdown of effective MLG systems - what we will name Type 0 MLG, even if some spontaneous negotiations may occur opportunistically and to shore up power and passage of policies.

We believe that such a conceptualisation could be useful to both MLG and federalism scholars as it can help to understand the actual and preferred negotiation systems that are seen over time in particular policy sectors. For example, applying this rather crudely to Troy's example, we can observe a movement in housing policy from a hierarchist (with an egalitarian ideal) to an individualist-focused negotiation model (with a bit of fatalism thrown in). In natural resource management there has been oscillation between all four categories, even though a number of our authors focus on the development of more egalitarian MLG approaches (e.g. Andrews; Norman and Gurran; Iwanicki et al.). Indigenous policy MLG systems, while also highly variable, can be productive when they lean towards egalitarian approaches, as in the COAG Murdi Paaki Trial (Jarvie and Stewart), but appear to be plagued with significant levels of fatalism (see above discussion regarding the NT Intervention approach) that, in the long term, creates one of the most detrimental (non)governance types. 
Taking this analysis further and looking more closely at the reform record of COAG, established in December 1992, we can also observe some underlying cultural value systems of various leaders in their approaches to negotiating specific policy issues through COAG. This history also illustrates the vulnerability of both Type I (more hierarchical, or at least focused on clear separation of powers) and Type II (both more egalitarian or individualist) multi-level policy processes to any shift in the supporting political environment. The ascension of Malcolm Turnbull to the prime ministership in September 2015, for example, was hailed as 'a potential game-changer', given the singular role of the prime minister in COAG agenda-setting and Turnbull's apparent willingness to have all reform options on the table (Tiernan 2015: 400-01).

The atmosphere at his first COAG meeting on 11 December, and at the leaders' retreat the previous day, reflected this new openness and optimism - a change in cultural and symbolic positioning - with the communiqué emphasising that a 'new' economic and federation reform agenda would be progressed through 'collaboration', 'shared responsibility' and employing 'a flexible approach' (COAG Communiqué, December 2015), that signalled a change from Type I (or 0) preferences to Type II MLG configurations. By the next COAG meeting in April, however, which was held in the context of increased fiscal pressures and pre-election political positioning, this positive environment for collaborative governance had evaporated: state and territory leaders showed little appetite for pursuing Turnbull's proposal (announced publicly) to levy income tax on their own behalf, and the development of a new competition- and productivityenhancing reform agreement was relegated to treasurers to produce (COAG Communiqué, April 2016) - a return to Type I configurations.

Yet, even in this inauspicious environment, it was notable that for two of COAG's wicked policy issues - Indigenous economic development and reducing violence against women and their children - there was recognition of the importance of community involvement in policy development. For example, leaders agreed to work in partnership with Indigenous leaders and communities to progress an Indigenous economic development framework. This shows, as discussed previously, that the MLG system type is policy-issue dependent and it is difficult to paint particular governments and their COAG working structures as just of one cultural complexion. Rather, requisite variety or varying percentages across the policy portfolio of issues exists and will remain in ongoing tension due to vying political interests. 
In summary, each one of these MLG systems authorises and legitimates the action of different groups of people (see Kerr) and holds its own coherent set of values and boundary-crossing (or sector-bridging) logics, which warrant further investigation in future research and policy practice. We hope that this conceptualisation will allow both researchers and policy practitioners to understand the MLG systems within which they work or have an interest, and how ongoing negotiations around Australian public policy for different issues might be strengthened and adapted into the future.

\section{Acknowledgements}

Adrian Kay and John Wanna are thanked for their review comments, which have helped to extend the quality of the discussion presented in this chapter.

\section{References}

Bache, I. \& Flinders, M. (eds) (2004). Multi-level Governance. Oxford University Press. doi.org/10.1093/0199259259.001.0001

COAG Communiqués (2015 \& 2016). www.coag.gov.au/meetingoutcomes [Accessed: 18/07/17].

Crase, L. (2011). The Fallout to the Guide to the Proposed Basin Plan. The Australian Journal of Public Administration, 70(1): 84-93. doi.org/ 10.1111/j.1467-8500.2011.00714.x

Daniell, K.A. (2011). Enhancing Collaborative Management in the Basin. In: Connell, D. \& Grafton, R.Q. (eds) Basin Futures: Water Reform in the Murray-Darling Basin. ANU E Press, Canberra, pp. 413-38, press.anu.edu.au/publications/basin-futures [Accessed: 31/05/2017].

(2012). Co-engineering and Participatory Water Management: Organisational Challenges for Water Governance. UNESCO International Hydrology Series, Cambridge University Press. doi.org/ 10.1017/CBO9780511998072 
. (2014). The Role of National Culture in Shaping Public Policy: A Review of the Literature. HC Coombs Forum Discussion Paper, June 2014, The Australian National University, Canberra, tinyurl.com/ national-culture-public-policy [Accessed: 29/12/2014].

Daniell, K.A., Coombes P.J. \& White, I. (2014). Politics of Innovation in Multi-level Water Governance Systems. Journal of Hydrology, 519(Part C): 2415-35. doi.org/10.1016/j.jhydrol.2014.08.058

Daniell, K.A., White, I. \& Rollin, D. (2009). Ethics and Participatory Water Planning. Proceedings of the 32nd Hydrology and Water Resources Symposium: 'H2009', 30 November - 3 December. Newcastle, pp. 1476-87.

David, A. (2000). La recherche-intervention, cadre général pour la recherche en sciences de gestion? In: David, A., Hatchuel, A. \& Laufer, R. (eds) Les nouvelles fondations des sciences en gestion. Vuibert, collection FNEGE, Paris, pp. 193-213.

Douglas, M. (1978). Cultural Bias. Occasional Paper No. 35. Royal Anthropological Institute of Great Britain and Ireland, London.

FaHCSIA (2011). Northern Territory Emergency Response Evaluation Report. Australian Government Department of Families, Housing, Community Services and Indigenous Affairs (FaHCSIA), Commonwealth of Australia, Canberra.

Fenna, A. (2012). Centralising Dynamics in Australian Federalism. Australian Journal of Politics and History, 58: 580-90. doi.org/10.1111/ j.1467-8497.2012.01654.x

Hamdhan, A. \& Lewis, C. (2013). The Home Insulation Program: a classic case of policy failure? www.academia.edu/11538221/The_ Home_Insulation_Program_A_Classic_Case_of_Policy_Failure [Accessed: 20/05/16].

Hanger, R.I. (2014). Report of the Royal Commission into the Home Insulation Program. Commonwealth of Australia, Canberra.

Hatchuel, A. \& Molet, H. (1986). Rational Modelling in Understanding and Aiding Human Decision-Making: About two case studies. European Journal of Operational Research, 24(1): 178-86. 
Hendriks, C.M. (2007). Praxis Stories: Experiencing interpretive policy research. Critical Policy Studies, 1(3): 278-300. doi.org/10.1080/194 60171.2007 .9518523

Hollander, R. \& Patapan, H. (2007). Pragmatic Federalism: Australian federalism from Hawke to Howard. Australian Journal of Public Administration, 66(3): 280-97. doi.org/10.1111/j.14678500.2007.00542.x

Hooghe, L. \& Marks, G. (2003). Unraveling the Central State, but How? Types of Multi-level Governance. Political Science Series. Institute for Advanced Studies, Vienna.

Hunter, B. (2007). Conspicuous Compassion and Wicked Problems: the Howard government's national emergency in Indigenous affairs. Agenda, 14(3): 35-54.

James, N. (2007). Keeping it Civil in Cases of Controversy, The Drum, 2 October, Australian Broadcasting Corporation, www.abc.net.au/ news/stories/2007/10/02/2048395.htm

Lasswell, H.D. (1936). Who Gets What, When and How. Whittlesey House, New York.

Leigh, A. \& Neill, C. (2010). Do Gun Buybacks Save Lives: Evidence from panel data. American Law and Economics Review, 12(2): 509-57. doi.org/10.1093/aler/ahq013

Marks, G. (1993). Structural Policy and Multilevel Governance in the EC. In: Cafruny, A. \& Rosenthal, G. (eds) The State of the European Community Vol. 2: The Maastricht Debates and Beyond. Longman, Harlow, pp. 391-410.

Mathews, R. (1977). Innovations and Developments in Australian Federalism. Publius, 7: 9-19. doi.org/10.2307/3329459

Matthews, M. (2009). Fostering Creativity and Innovation in Cooperative Federalism - the uncertainty and risk dimensions. In: Wanna, J. (ed.) Critical Reflections on Australian Public Policy. ANU E Press, Canberra, pp. 59-70, epress.anu.edu.au/anzsog/critical/pdf/ch06.pdf [Accessed: 29/12/14]. 
McCann, E. \& Ward, K. (2012). Assembling Urbanism: following policies and 'studying through' the sites and situations of policy making. Environment and Planning A, 44: 42-51. doi.org/10.1068/a44178

Midgley, G. (2000). Systemic Intervention: Philosophy, methodology, and practice. Kluwer Academic/Plenum Publishers, New York. doi.org/10.1007/978-1-4615-4201-8

Mosse, D. (2004). Is Good Policy Unimplementable? Reflections on the Ethnography of Aid Policy and Practice. Development and Change, 35: 639-71. doi.org/10.1111/j.0012-155X.2004.00374.x

(2011). Politics and Ethics: ethnography of expert knowledge and professional identities. In: Shore, C., Wright, S. \& Pero, D. (eds) Policy Worlds: Anthropology and the Analysis of Contemporary Power, Berghahn Books, New York and Oxford, pp. 50-67.

Mukhtarov, F. \& Daniell, K.A. (2017). Diffusion, Adaptation and Translation of Water Policy Models. In: Conca, K. \& Weinthal, E. (eds) The Oxford Handbook of Water Politics and Policy. Oxford University Press.

Painter, M. (2001). Multi-level Governance and the Emergence of Collaborative Federal Institutions in Australia. Policy and Politics, 29: 137-50. doi.org/10.1332/0305573012501260

Peck, J. \& Theodore, N. (2012). Follow the Policy: a distended case approach. Environment and Planning A, 44: 21-30. doi.org/10.1068/ a44179

Peters, B.G. \& Pierre, J. (2004). Multi-level Governance and Democracy: a 'Faustian bargain'? In: Bache, I. \& Flinders, M. (eds) Multilevel Governance. Oxford University Press, pp. 75-89. doi.org/ $10.1093 / 0199259259.003 .0005$

Prasser, S. (2006). Aligning 'Good Policy' with 'Good Politics'. In Colebatch, H.K. (ed.) Beyond the Policy Cycle: The Policy Process in Australia. Allen and Unwin, Sydney.

Sanders, W. (2008). In the Name of Failure: a generational revolution in Indigenous affairs. In: Aulich, C. \& Wettenhall, R. (eds) Howard's Fourth Government: Australian Commonwealth Administration 2004-2007. UNSW Press, Sydney, pp. 187-205. 
Shergold, P. (2015). Learning from Policy Failure. Why Large Government Policy Initiatives Have Gone So Badly Wrong in the Past and How the Chances of Success in the Future Can Be Improved. Commonwealth of Australia, Canberra.

Smullen, A. (2014). Conceptualising Australia's Tradition of Pragmatic Federalism. Australian Journal of Political Science, 49(4): 677-93. doi.org/10.1080/10361146.2014.964660

Stewart, J. \& Jarvie, W. (2015). Haven't We Been This Way Before? Evaluation and the Impediments to Policy Learning. Australian Journal of Public Administration, 74(2): 114-127. doi.org/10.1111/14678500.12140

Thompson, M., Ellis, R. \& Wildavsky, A. (1990). Cultural theory. Westview Press, Boulder, Colorado.

Tiernan. A. (2015). Reforming Australia's Federal Framework: priorities and prospects. Australian Journal of Public Administration, 74(4): 398-405. doi.org/10.1111/1467-8500.12180

Tukker, A. \& Butter, M. (2007). Governance of Sustainable Transitions: About the 4(0) ways to change the world. Journal of Cleaner Production, 15(1): 94-103. doi.org/10.1016/j.jclepro.2005.08.016

Wagenaar, H. (2006). Interpretive Policy Analysis. In: Fischer, F., Miller, G. \& Sidney, M. (eds) The Handbook of Public Policy Analysis: Theory, Politics and Methods. Boca Raton, CRC Press, pp. 429-41. doi.org/ 10.1201/9781420017007.ch29

Walter, J. (2010). What Were They Thinking? The Politics of Ideas in Australia. UNSW Press, Sydney.

Wedel, J., Shore, C., Feldman, G. \& Lathrop, S. (2005). Towards an Anthropology of Public Policy. Annals of the American Academy of Political and Social Science, 600: 30-51. doi.org/10.1177/ 0002716205276734

Wettenhall, R. (2011). Global Financial Crisis: the Australian experience in international perspective. Public Organization Review, 11(1): 77-91. doi.org/10.1007/s11115-010-0149-9 
Wild, R. \& Anderson, P. (2007). Ampe Akelyernemane Meke Mekarle: 'Little Children are Sacred', Report of the Northern Territory Board of Inquiry into the Protection of Aboriginal Children from Sexual Abuse 2007. Department of the Chief Minister, Northern Territory.

Wildavsky, A. (1987). Choosing Preferences by Constructing Institutions: a cultural theory of preference formation. American Political Science Review, 81(1): 3-21. doi.org/10.2307/1960776

Yanow, D. (2000). Conducting Interpretive Policy Analysis. Sage, Thousand Oaks. doi.org/10.4135/9781412983747 
This text is taken from Multi-level Governance: Conceptual challenges and case studies from Australia, edited by Katherine A. Daniell and Adrian Kay, published 2017 by ANU Press, The Australian National University, Canberra, Australia.

dx.doi.org/10.22459/MG.11.2017.18 